\title{
O TRABALHADOR COM DEFICIÊNCIA NA ORGANIZAÇÃO: UM ESTUDO SOBRE O TREINAMENTO E DESENVOLVIMENTO E A ADEQUAÇÃO DAS CONDIÇÕES DE TRABALHO
}

\author{
Andréia Maria de Carvalho Maia \\ deiammaia@yahoo.com.br \\ Maria Nivalda de Carvalho-Freitas \\ nivalda@ufsj.edu.br
}

Universidade Federal de São João del-Rei - São João del-Rei, MG / Brasil

http://dx.doi.org/10.1590/1413-2311.0722014.54834

Recebido em 08/12/2014

Aprovado em 21/12/2015

Disponibilizado em 31/12/2015

Avaliado pelo sistema "double blind review"

Revista Eletrônica de Administração

Editor: Luís Felipe Nascimento

ISSN 1413-2311 (versão "on line")

Editada pela Escola de Administração da Universidade Federal do Rio Grande do Sul.

Periodicidade: Quadrimestral

Sistema requerido: Adobe Acrobat Reader

\section{RESUMO}

Mesmo apoiados por leis que medeiam a inclusão da diversidade, ainda é difícil o acesso de pessoas com deficiência ao mercado de trabalho, o que muitas vezes é justificado pela baixa qualificação profissional delas ou dificultado pelas práticas adotadas pelas empresas. A pesquisa investigou as pessoas com deficiência, os profissionais de recursos humanos e os profissionais de segurança no trabalho de duas empresas para avaliar como é realizada a inserção das pessoas com deficiência dentro das organizações mediante o treinamento e desenvolvimento e sua adaptação ao ambiente de trabalho, considerando que já se passaram 23 anos da aprovação da Lei de Cotas no Brasil. Os resultados demonstram que a Lei de Cotas e o tipo de deficiência ainda influenciam no processo de contratação. Os programas de treinamento e desenvolvimento adotados não utilizam estratégias metodológicas ou tecnologias assistivas para garantir igualdade de oportunidades para as pessoas com deficiência. São realizados preferencialmente treinamentos on-the-job. Nem todos os respondentes reconhecem a qualificação profissional como fundamental no momento da contratação, principalmente porque a contratação de pessoas com deficiência é eminentemente para funções operacionais. Por outro lado, grande parte das pessoas com deficiência se sente satisfeita e valorizada no seu trabalho. As adaptações no ambiente e o uso de tecnologias assistivas foram reconhecidos como importantes para o desempenho desse grupo.

Palavras-chave: Deficiência; inclusão; T\&D; tecnologia assistiva; qualificação profissional. 


\title{
O TRABALHADOR COM DEFICIÊNCIA NA ORGANIZAÇÃO: UM ESTUDO SOBRE O TREINAMENTO E DESENVOLVIMENTO E A ADEQUAÇÃO DAS CONDIÇÕES DE TRABALHO
}

THE WORKER WITH DISABILITIES IN THE ORGANIZATION: A STUDY ON

\author{
TRAINING AND DEVELOPMENT AND THE ADEQUACY OF WORKING \\ CONDITIONS
}

\begin{abstract}
Even supported by laws that mediate the inclusion of diversity, the people with disabilities still have difficulty to access the job market, which is often justified by their low level of qualification or hindered by policies adopted by the companies. This research investigated the people with disabilities, the professionals of Human Resources and the professionals of Work Safety Departments of two companies to evaluate how the inclusion of people with disabilities is carried out by the organizations through training and development, and the people's with disabilities adaptation on the job, considering that it is been 23 years of the approval of Quota Law in Brazil. The results show that the Quota Law and the type of disability still influence the hiring process. The training and development programs adopted do not use methodological strategies or assistive technologies to ensure equal opportunities for people with disabilities. On-the-job trainings are preferably performed. Not all respondents recognize the professional qualification as fundamental in the hiring process, mainly because people with disabilities are eminently hired for operational functions. On the other hand, the majority of people with disabilities feel valued and satisfied in their work. The environment adaptations and the use of assistive technologies were recognized as important for the performance of this group.
\end{abstract}

Keywords: Disability; Inclusion; T \& D; Assistive Technology; Professional Qualification.

\section{EL TRABAJADOR CON DEFICIENCIA EN LA ORGANIZACIÓN: UN ESTUDIO SOBRE EL ENTRENAMIENTO Y DESARROLLO Y LA ADECUACIÓN DE LAS CONDICIONES DE TRABAJO}

\section{RESUMEN}

Incluso con el apoyo de las leyes que median la inclusión de la diversidad, es todavía difícil el acceso para las personas con deficiencia al mercado de trabajo, el que muchas veces se justifica por la baja cualificación de estas personas u obstaculizado por las prácticas adoptadas por las empresas. El estudio investigó las personas con deficiencia, los profesionales de recursos humanos y los profesionales de seguridad en el trabajo de dos empresas para evaluar como se realiza la inclusión de personas con deficiencia dentro de las organizaciones mediante la entrenamiento y el desarrollo y su adaptación al lugar de trabajo, considerando que ahora han pasado 23 años de la aprobación de la Ley de Cuotas en Brasil. Los resultados muestran que la Ley de Cuotas y el tipo de deficiencia aún influyen en el proceso de contratación. Los programas de entrenamiento y el desarrollo adoptados no utilizan estrategias metodológicas o las tecnologías de asistencia para asegurar la igualdad de oportunidades para personas con deficiencia. Preferiblemente se llevan a cabo la

REAd | Porto Alegre - Edição 82 - N 3 - setembro/dezembro 2015 - p. 689-718 
entrenamiento on-the-job. No todos los entrevistados reconocen la cualificación como esencial en el momento de la contratación, principalmente porque la contratación de personas con deficiencia es eminentemente para funciones operacionales. Por otro lado, la mayoría de las personas con deficiencia se sienten satisfechos y valorados en su trabajo. Las adaptaciones en el lugar de trabajo y el uso de tecnologías de asistencia fueron reconocidos como importantes para el desempeño de este grupo.

Palabras Clave: Deficiencia; inclusión; E \& D; tecnología de asistencia; cualificación profesional.

\section{INTRODUÇÃO}

A inserção e gestão das pessoas com deficiência têm ganhado destaque nos estudos atuais por ser uma das mudanças que vêm ocorrendo no contexto organizacional (CARVALHO-FREITAS, 2007; GOULART; COIMBRA, 2008).

Os estudos realizados no Brasil, por exemplo, têm se direcionado, principalmente, a analisar as dificuldades e facilidades vividas pelas pessoas com deficiência em se inserirem e se manterem no mercado de trabalho. Além dessa questão, os estudos também revelam a preocupação em avaliar as práticas de gestão adotadas pelas organizações em relação a essa dimensão da diversidade (CARVALHO-FREITAS; MARQUES, 2007).

O Censo realizado em 2010, pelo Instituto Brasileiro de Geografia e Estatística (IBGE) e divulgado pelo Ministério da Fazenda (BRASIL, 2012), revelou que aproximadamente $24 \%$ da população brasileira possuem algum tipo de incapacidade ou deficiência, o que equivale a 46 milhões de pessoas com pelo menos alguma dificuldade de enxergar, de ouvir, de locomover-se ou com alguma deficiência física ou intelectual.

Nos Estados Unidos, as PcDs formam o maior grupo minoritário do país. A proporção de pessoas com deficiência naquele país é de um para cada cinco indivíduos sem deficiência e a previsão é que 30\% das pessoas sem deficiência terão alguma deficiência durante seus anos de trabalho (STONE-ROMERO; STONE; LUKASZEWISKI, 2006).

Também nos Estados Unidos, dados revelam que apenas 31,4\% das PcDs estão empregadas, em comparação com 84\% das pessoas sem deficiência (Stone-Romero et al., 2006). No Brasil, de acordo com os dados divulgados na Relação Anual de Informações Sociais (RAIS) (2012), aproximadamente 330 mil pessoas com deficiência estão empregadas, representando 0,7\% do total de vínculos empregatícios ativos do País.

Não se pode negar que o número de PcDs que entram no mercado de trabalho vem aumentando, mas há muitas evidências de que elas têm sofrido desvantagem nesse campo. Segundo Stone-Romero et al. (2006), a maioria recebe baixos salários ou vive abaixo do nível REAd | Porto Alegre - Edição 82 - N 3 - setembro/dezembro 2015 - p. 689-718 


\section{O TRABALHADOR COM DEFICIÊNCIA NA ORGANIZAÇÃO: UM ESTUDO SOBRE O TREINAMENTO E DESENVOLVIMENTO E A ADEQUAÇÃO DAS CONDIÇÕES DE TRABALHO}

da pobreza. Poucas têm oportunidades de experimentar um trabalho gratificante, o que afeta não só sua autoestima, como também propaga a estigmatização (STONE-ROMERO et al., 2006).

A inclusão proporciona à organização benefícios como a adoção de uma imagem positiva perante o consumidor. Mesmo diante da necessidade e dos benefícios, a PcD se depara com dificuldades nesse processo de inclusão, que vão desde uma percepção negativa sobre suas possibilidades educacionais, discriminação, falta de conhecimento de sua capacidade, segregação no ambiente de trabalho, desconhecimento dos pares acerca do que seja deficiência e falta de adequação das condições e práticas de trabalho nas empresas (COIMBRA; GOULART, 2009).

Embora haja políticas públicas com leis voltadas para as PcDs, como por exemplo, a Lei de $\operatorname{Cotas}^{1}$, estudos têm apontado dificuldades para o cumprimento dessas leis e, consequentemente, para a inclusão das PcDs no trabalho, tais como: barreiras arquitetônicas (inclui-se aqui dificuldade de transporte); desconhecimento em relação ao que é a deficiência; resistências por parte de chefias e gerentes; atitude protecionista da família; baixa escolaridade e qualificação profissional; falta de flexibilização em relação ao perfil exigido; falta de recursos das instituições para qualificação profissional; e receio em renunciar ao Benefício de Prestação Continuada (BPC) (TANAKA, MANZINI, 2005; SHIMONO, 2008; DELGADO, GOULART, 2011). Além disso, há o medo de serem autuadas pelo não cumprimento da lei e de terem que pagar multas (CARVALHO, 2011). Diante desses argumentos, principalmente, baixa escolaridade e qualificação profissional, a queixa das empresas se fundamenta na explicação: “queremos contratar (e cumprir a lei), mas não há candidatos que atendam às nossas vagas”.

Outro questionamento encontrado em algumas pesquisas (SOUZA, 2010; BEZERRA, VIEIRA, 2012) é um contraponto em relação à dificuldade citada. Se, por um lado, as pessoas com deficiência devem se preparar para entrar no mercado de trabalho, por outro, os setores de Recursos Humanos das organizações têm desenvolvido práticas de gestão dessas pessoas que minimizam as desvantagens desse grupo?

Para Ribas (2009), as empresas devem superar a preocupação de contratar PcDs por submissão a uma lei e começarem a efetivar ações e estratégias de modo a inserirem e manterem esses trabalhadores no mundo do trabalho. É preciso pensar possibilidades de

\footnotetext{
${ }^{1}$ Lei de Cotas é o nome popular da Lei 8.213, de 24 de julho de 1991, que obriga empresas com 100 ou mais funcionários a preencher de 2 a $5 \%$ dos seus cargos com beneficiários reabilitados ou pessoas com deficiência.

REAd | Porto Alegre - Edição 82 - N 3 - setembro/dezembro 2015 - p. 689-718
} 
desenvolvimento e ascensão destes, buscar métodos eficazes para qualificá-las e gerir suas potencialidades. Às PcDs, cabe também demonstrarem seu valor, apresentarem sua autonomia e independência e desenvolverem seu crescimento profissional, a fim de atenderem às metas das empresas e alcançarem os resultados esperados por elas quanto ao desempenho de seus funcionários.

Em um estudo que analisou as publicações internacionais sobre a deficiência e trabalho, Carvalho-Freitas, Leal e Souto (2011) levantaram vários artigos que consideraram empregadores, profissionais de RH e colegas de trabalho como público de estudo. Segundo o levantamento dos pesquisadores, abarcar as pessoas que se relacionam diretamente com as PcDs no ambiente de trabalho auxilia na compreensão das barreiras de acesso que as PcDs têm ao trabalho.

Diante do exposto, esta pesquisa se propõe a investigar o processo de inclusão das PcDs nas organizações, focando as práticas de treinamento e desenvolvimento (T\&D), além dos recursos de adequação e adaptação utilizados nesses processos. A investigação propõe-se a considerar tanto a percepção das próprias pessoas com deficiência quanto dos profissionais de recursos humanos (RH) e de segurança no trabalho (ST) envolvidos nesse processo, a fim de levantar as dificuldades ainda presentes e os progressos já realizados na vivência desse processo de inclusão da diversidade.

\section{REFERENCIAL TEÓRICO}

\subsection{Contextualizando a deficiência}

A questão da deficiência é um tema discutido há muito tempo. Desde a Grécia antiga, ela já é abordada e acompanhada por um processo histórico de exclusão. No entanto, somente a partir de 1960, é que se iniciaram os movimentos sociais que buscavam promover a reinserção das pessoas com deficiência (CARVALHO, 2011).

Em congruência com essa evolução sócio-histórica, também a construção de uma terminologia adequada para referir-se às pessoas com deficiência passou por um processo de evolução. Termos como “excepcional”, “pessoa deficiente” e “pessoa portadora de deficiência” foram amplamente utilizados, até se adotar, hoje, o termo "pessoa com deficiência” como o mais adequado. O termo, inclusive, foi referendado pela Portaria $n^{\circ}$ 2.344, de 3 de novembro de 2010 (SECRETARIA DE DIREITOS HUMANOS, 2010).

REAd | Porto Alegre - Edição 82 - N 3 - setembro/dezembro 2015 - p. 689-718 
O TRABALHADOR COM DEFICIÊNCIA NA ORGANIZAÇÃO: UM ESTUDO SOBRE O TREINAMENTO E DESENVOLVIMENTO E A ADEQUAÇÃO DAS CONDIÇÕES DE TRABALHO

O próprio conceito de “deficiência” não apresenta um consenso acerca de sua interpretação. Carvalho-Freitas (2007) a define como sendo “o produto da articulação entre condição biológica e contingências históricas, sociais e espaciais, o qual poderá resultar numa maior ou menor possibilidade de discriminação ou inserção social das pessoas com deficiência” (p. 24).

Somente em 2001, foi aprovada, pela Organização Mundial de Saúde (OMS), a Classificação Internacional de Funcionalidade, Deficiência e Saúde (CIF) - The International Classification of Functioning, Disability and Health (ICF). A conceituação CIF considera três dimensões de funcionamento humano: o funcionamento no nível do corpo, ou seja, quais processos corporais são afetados; o funcionamento estrutural, que diz respeito às partes lesionadas ou que membros faltam; e o relacionamento do corpo com o meio, isto é, de como as relações são afetadas pela deficiência. Essas dimensões englobam funções corporais básicas, bem como as capacidades humanas para realizar ações, comportamentos e papéis (BICKENBACH, 2012; FARIAS, BUCHALLA, 2005).

A atual estrutura funcional social, pautada na valorização de mão de obra eficiente e no culto do corpo perfeito, acaba por negar a deficiência pelo fato de esta remeter à ideia de falta e impossibilidade. Exalta-se o corpo saudável, aquele pronto para competir no mercado de trabalho, enquanto aquele fora de ordem é um empecilho para a eficiência da produção (SILVA, 2006).

A questão que emerge, ao se tratar da deficiência, é que o relacionamento com uma PcD traz alguns incômodos. A aceitação da deficiência ou do diferente promove medo e receios. Há o medo de identificação com o diferente e, portanto, de se ver também como possuidor de limitações. Muitas pessoas também não sabem lidar com PcDs, e isso causa um incômodo, já que nossas relações interpessoais contemporâneas baseiam-se na previsibilidade, e o fato de não convivermos com muitas delas promove um estranhamento quando o temos de fazer (SILVA, 2006). É o que o estudo de Delgado e Goulart (2011) exemplifica. Na instituição estudada, no início, os funcionários se sentiram constrangidos pela presença das PcDs no ambiente de trabalho, mas, com o tempo e uma melhor convivência, os funcionários perceberam que as PcDs estavam só buscando legitimar seus direitos como cidadãos.

O modo pelo qual as pessoas percebem a deficiência é um indicador de como elas se relacionam com as PcDs. Carvalho-Freitas (2007) realizou uma análise histórica e percebeu a existência de diferentes concepções de deficiência que se pautavam em matrizes de 
interpretação dominantes. Essas matrizes foram desenvolvidas após a observação de padrões de pensamento e comportamento em relação à deficiência que predominavam em diferentes períodos históricos e que reapareciam em outras épocas, podendo ser encontradas nos contextos atuais. A partir desse estudo, Carvalho-Freitas (2007) definiu seis matrizes interpretativas da deficiência.

Na Matriz da Subsistência/Sobrevivência as pessoas são aceitas ou não de acordo com suas capacidades de contribuir para o desenvolvimento da sociedade. Nesta concepção, as pessoas que possuem alguma deficiência ou deformidade são excluídas por serem avaliadas $a$ priori como incapazes de trabalhar de forma plena e contribuir nesse processo de manutenção da sobrevivência do povo, já que não retratam o ideal de vigor e força. Sendo assim, segundo esta matriz, para serem aceitas as PcDs devem se esforçar muito mais que as pessoas “normais” para demonstrar e comprovar sua capacidade de contribuir para a produção social.

Na Matriz da Sociedade Ideal e a Função Instrumental da Pessoa, almeja-se uma sociedade ideal. As PcDs, além de se distanciarem de um padrão de perfeição física, também eram vistas como improdutivas e alvo de descaso do Estado que reduzia os gastos e recursos com essas pessoas. Ainda, é possível identificar essa concepção quando há a recusa de algumas pessoas em frequentar os mesmos lugares que uma $\mathrm{PcD}$, ou em expressões agressivas que afirmam que as PcDs são um peso para o orçamento público ou que deveriam ser eliminadas, como no caso de grupos neonazistas.

A Matriz da Deficiência Como Fenômeno Espiritual se pauta na influência da doutrina cristã, por isso a concepção de deficiência estava submetida a algo espiritual, sendo percebida ora como eleição divina, ora como castigo de Deus ou possessão demoníaca. As PcDs passam a ser acolhidas em instituições asilares ou abrigos mantidos por caridade da Igreja e de outras pessoas. Embora cuidadas por essas instituições, as PcDs são marcadas pela segregação, dependentes da compaixão e caridade de outros, sem status moral e negadas em seus direitos de cidadãs. Ainda, encontram-se manifestações atuais que colocam as PcDs como “anjos” e objetos de caridade e compaixão, demonstrando a atualidade desta concepção.

A Matriz da Normalidade surge em meio ao desenvolvimento do mundo científico, do conhecimento e da técnica, da manufatura e da medicina. A deficiência passa a ser vista como uma manifestação de doença, que deve ser diagnosticada e tratada por médicos e em instituições especializadas para esse fim. Neste caso, há um padrão de normalidade. Aquele que se desvia desse padrão é considerado “anormal” e precisa ser reabilitado, melhorado, para se enquadrar nos padrões da sociedade. Essa matriz é perceptível em atitudes que colocam a

REAd | Porto Alegre - Edição 82 - N 3 - setembro/dezembro 2015 - p. 689-718 


\section{O TRABALHADOR COM DEFICIÊNCIA NA ORGANIZAÇÃO: UM ESTUDO SOBRE O TREINAMENTO E DESENVOLVIMENTO E A ADEQUAÇÃO DAS CONDIÇÕES DE} TRABALHO

deficiência como critério de lotação de determinadas vagas de trabalho ou a colocação da pessoa em um setor à parte, separada dos outros funcionários.

Na Matriz da Inclusão Social as ações ou intenções são direcionadas a modificar a sociedade para que ela se torne acessível a todos. Ou seja, a deficiência perde o caráter de atributo individual e passa a ser vista como uma questão social. É uma matriz recente, originada no século XX, período em que surgiram no mundo inteiro instituições especializadas no atendimento das deficiências, programas de reabilitação e movimentos sociais em prol das minorias.

Por último, há a Matriz Técnica em que a diversidade e, consequentemente, a deficiência, é um recurso técnico que as organizações devem gerenciar e que possibilitará não apenas a inclusão real das PcDs no trabalho, como também trará grandes vantagens para a organização, que será bem vista por clientes, funcionários e a sociedade em geral, propiciando um clima organizacional favorável.

A concepção da deficiência a partir da Matriz da Inclusão Social é a que tem norteado muitos estudos sobre deficiência na atualidade, inclusive esse. Essa concepção se pauta no paradigma do Modelo Social da Deficiência.

O Modelo Social da Deficiência surge como resultado da frustração de profissionais com deficiência em relação à forma como a deficiência estava sendo tratada pelo Estado e pela sociedade em geral. O movimento foi marcado com a criação da Union of the Physically Impaired Against Segregation (UPIAS), por Paul Hunt, Vic Finkelstein e Lennard Davis, no Reino Unido. Até então, a solução social para a questão da deficiência era pela institucionalização das PcDs e do assistencialismo. A UPIAS surge como crítica a essas ações e se propõe a combater a segregação das PcDs por entender que o problema não está nas disfunções ou na falta de renda das PcDs, mas na dificuldade da própria sociedade em se relacionar com essas pessoas vistas como infelizes, inúteis ou doentes, o que promovia a segregação e exclusão (BARNES, 2012).

A perspectiva do modelo social não nega a importância das intervenções individuais médicas ou da reabilitação. Em vez disso, chama a atenção para as limitações dessas práticas em relação à autonomia e independência das PcDs. Outro princípio do modelo social é que ele busca desviar o foco das limitações funcionais das PcDs para os problemas causados pelas desativações ambiental e cultural e pelas barreiras (BARNES, 2012).

REAd | Porto Alegre - Edição 82 - Nº 3 - setembro/dezembro 2015 - p. 689-718 
Em suma, esse novo modelo surge como reflexão sobre as tendências incapacitantes da sociedade moderna, a fim de proporcionar a criação de políticas e práticas que facilitem sua erradicação (BARNES, 2012).

\subsection{Qualificação profissional, T\&D e tecnologia assistiva}

A revolução tecnológica hoje tem causado grande impacto no modo de produção, mas também nas relações homem-trabalho, afetando a própria qualificação profissional. A globalização demanda cada vez mais serviços e produtos de alta qualidade, o que, por sua vez, exige o desenvolvimento tecnológico e promove um mercado cada vez mais competitivo (BASTOS, 2006; MOURÃO, PUENTE-PALACIOS, 2006). A competitividade, por sua vez, exige produtividade com qualidade, requerendo trabalhadores qualificados (GOULART; GUIMARÃES, 2010).

O sistema capitalista trouxe a formação profissional especializada tal como é adotada hoje, perpassando o processo educacional da pessoa e discutida por diversos setores, a fim de atender as necessidades do sistema de produção (MOURÃO; PUENTE-PALACIOS, 2006).

A formação profissional é um processo de aquisição de conhecimentos teóricos, técnicos e operacionais, por meio de escolas e empresas, que visa a capacitar o trabalhador para a produção de bens ou serviços. É um processo constante para exercer determinada profissão e que não foca o treinamento de uma habilidade específica (MOURÃO; PUENTEPALACIOS, 2006).

Diante dessas mudanças, Bastos (2006) salienta dois novos desafios que se apresentam para as organizações e para a sociedade. O primeiro deles é a fragilização ou precarização do emprego, ou seja, o desemprego que é decorrente dessas mudanças tecnológicas; o segundo é a qualificação. Para o autor, esses fenômenos estão associados ao conceito de empregabilidade, de modo que cabe ao trabalhador e à organização refletirem sobre o papel de cada um no processo de qualificação e permanência do trabalhador no mercado de trabalho.

Apesar de não ser a única responsável por garantir um emprego, a qualificação tem sua relevância nesse processo de entrada e permanência no mercado de trabalho, e deve ser oferecida pelo maior número de setores e instituições possíveis. Para Goulart e Guimarães (2010), a busca pela qualificação deve ser um interesse de toda a sociedade.

REAd | Porto Alegre - Edição 82 - N 3 - setembro/dezembro 2015 - p. 689-718 
O TRABALHADOR COM DEFICIÊNCIA NA ORGANIZAÇÃO: UM ESTUDO SOBRE O
TREINAMENTO E DESENVOLVIMENTO E A ADEQUAÇÃO DAS CONDIÇÕES DE TRABALHO

Para Birchal e Muniz (2010) é de interesse da estrutura política das empresas assegurar que os funcionários permaneçam na empresa, por isso elas têm cada vez mais investido na gestão de carreira de seu pessoal. Neste novo contexto organizacional, as carreiras deixaram de ser verticalizadas para se tornarem horizontalizadas. A organização, portanto, assume interesse quanto à empregabilidade de seus trabalhadores, fornecendo a eles chances de se autoaperfeiçoarem.

Uma das formas de as empresas contribuírem para esse aperfeiçoamento profissional é mediante ações de treinamento e desenvolvimento (T\&D).

O treinamento de pessoas é uma ação, um projeto sistemático, planejado e conduzido pela organização e realizado dentro de um período específico de tempo. O objetivo da organização é aumentar a efetividade de determinado setor ou grupo de trabalhadores, de modo que isso reflita numa melhora de desempenho desses trabalhadores na realização de determinadas tarefas. As ações de treinamento são voltadas para a aquisição, modificação ou ampliação e desenvolvimento de habilidades, sejam elas motoras, cognitivas ou interpessoais, dependendo do objetivo do treinamento a ser realizado (VARGAS; ABBAD, 2006).

Alguns estudos (SUZANO et al., 2009; BAHIA, SANTOS, 2009; RIBEIRO, CARNEIRO, 2009; DELGADO, GOULART, 2011) perceberam que, apesar da qualificação ser um ponto de dificuldade, as empresas buscam contornar esse obstáculo e trabalhar a qualificação dentro da própria empresa, demonstrando uma disposição em trabalhar com as PcDs.

Para Ribeiro e Ribeiro (2009) as empresas podem investir em estratégias como o desenvolvimento de networks, mentoring, treinamentos on-the-job, programas de qualificação, integração com estimulação de diálogo entre funcionários, além de modelos de troca de papéis, como possibilidades de trabalhar a inserção de trabalhadores com deficiência.

O desenvolvimento de pessoas também promove a aprendizagem de trabalhadores para que possam ajudar a organização no alcance de seus resultados. Porém, essa aprendizagem é voltada para o crescimento individual, propiciando um amadurecimento dos trabalhadores, sem uma relação direta com algum posto de trabalho. O treinamento, muitas vezes, é reconhecido como parte integrante do desenvolvimento de pessoas (VARGAS; ABBAD, 2006).

Por serem tão próximos e muitas vezes utilizados em conjunto, é comum o uso da expressão “treinamento e desenvolvimento” (T\&D). Vargas (1996) conceitua a expressão 
como uma aquisição sistemática de conhecimentos - conceitos, valores ou normas - e aprendizagem de novas habilidades, de modo a promover mudanças no modo de ser e pensar do indivíduo. Nesse caso, o processo pode ser a curto ou longo prazo.

O processo de T\&D aqui definido se propõe a desenvolver competências. E, por isso, o modelo de gestão de competências foi o adotado neste estudo.

Para Bastos (2006), a competência se confronta com a qualificação, já que elas são muitas vezes confundidas na área organizacional. Porém, a competência apresenta uma lógica mais individualizada, enquanto a qualificação, por possuir uma relação com o social e o político, depende dos interesses sociais e políticos que lhe favoreçam ser desenvolvida. A competência diz respeito "à capacidade de o sujeito lidar com cada situação ou evento, mobilizando recursos pessoais adequados para oferecer respostas à situação" (BASTOS, 2006, p. 34).

A fim de avaliar a eficácia de ações de T\&D e, consequentemente, gerir ações futuras neste setor, Borges-Andrade (2006) desenvolveu o Modelo de Avaliação Integrado e Somativo (MAIS). Esse modelo possibilita não só avaliar os efeitos imediatos e mediatos, mas também permite apontar quais componentes se relacionam a esses resultados. De posse desses dados o gestor pode avaliar se determinada ação de T\&D alcançou os resultados propostos e, ainda, definir o que pode ser feito para efetivar os próximos eventos de T\&D (BORGES-ANDRADE et al., 2013).

Nesse modelo há quatro componentes internos (relativos ao sistema de T\&D). Os insumos dizem respeito às questões e características físicas e sociais e aos estados comportamentais e cognitivos anteriores ao treinamento e que podem influenciar na realização ou nos resultados obtidos; os procedimentos são as ações e cuidados necessários para facilitar ou produzir os resultados esperados no treinamento; os processos tratam dos aspectos comportamentais dos participantes, à medida que o treinamento é realizado e os resultados são a demonstração do sucesso ou fracasso inicial dos programas de treinamento voltados ao desempenho dos aprendizes.

Há também quatro componentes externos (do ambiente organizacional). As necessidades levantam as lacunas entre o desempenho esperado e o que é realizado por indivíduos, grupos ou setores, sendo a base para a organização de um programa de treinamento; o suporte engloba os aspectos que propiciam uma melhor aplicação no trabalho do que foi aprendido, sejam físicos, motivacionais ou psicossociais, de âmbito familiar, escolar, organizacional ou comunitário; a disseminação diz respeito à forma como a ação de 


\section{O TRABALHADOR COM DEFICIÊNCIA NA ORGANIZAÇÃO: UM ESTUDO SOBRE O TREINAMENTO E DESENVOLVIMENTO E A ADEQUAÇÃO DAS CONDIÇÕES DE} TRABALHO

treinamento foi planejada, de modo a atrair os participantes ou facilitar a aceitação de sua realização e os efeitos a longo prazo são as consequências ambientais do treinamento nos indivíduos, nas equipes e na organização, podendo incluir efeitos esperados ou inesperados, desejáveis ou indesejáveis.

No estudo realizado por Delgado e Goulart (2011), mesmo sem a adoção de um programa de treinamento específico para as PcDs, elas relataram que as ações de T\&D ofertadas pela empresa eram ferramentas cruciais de transformação do ambiente de trabalho. O treinamento de ambientação (introdutório) era voltado para a padronização dos CHAs (Conhecimentos, Habilidades e Atitudes) das PcDs de acordo com as expectativas da instituição. Mas, além disso, esse treinamento promovia a conscientização dos outros funcionários da importância de adequação das condições de trabalho e do desenvolvimento das PcDs após a contratação, o que promovia resultados positivos. Para as PcDs é fundamental participar de treinamentos e cursos, como também a paciência e a interação, pois são fatores que facilitam a inserção no mercado e aumentam a probabilidade de futuras promoções no trabalho. Em contrapartida, reconhecem a importância de elas próprias investirem em tempo e esforço (DELGADO; GOULART, 2011).

O fato de o treinamento ser igual para todos os funcionários (com e sem deficiência) trouxe dificuldades para as PcDs que relataram, por exemplo, que a falta de intérprete, foi um impedimento para o melhor aproveitamento das ações de T\&D. Cabe ressaltar que o argumento dos gestores para a realização de um treinamento único para trabalhadores com e sem deficiência era de promover uma política de iguais oportunidades, o que para as PcDs não é visto como vantajoso, já que não há uma adaptação às suas necessidades (DELGADO; GOULART, 2011).

Sendo assim, as adaptações e o uso de recursos que facilitem essa adequação ambiental também são importantes. Os recursos de Tecnologia Assistiva (TA) são um exemplo.

É possível encontrar a utilização de ajudas tecnológicas desde a Antiguidade, como bengalas, ganchos e mãos de madeira, entre outros recursos (GARCIA; GALVÃO FILHO, 2012). Com esses exemplos, percebe-se que a TA não se refere apenas a aparatos de origem eletrônica ou informatizados.

REAd | Porto Alegre - Edição 82 - N 3 - setembro/dezembro 2015 - p. 689-718 
Segundo o Comitê de Ajudas Técnicas (CAT) - responsável por estudos e proposição de políticas públicas da Secretaria Especial dos Direitos Humanos da Presidência da República (SEDH/PR) - a Tecnologia Assistiva pode ser conceituada como

(...) uma área do conhecimento, de característica interdisciplinar, que engloba produtos, recursos, metodologias, estratégias, práticas e serviços que objetivam promover a funcionalidade, relacionada à atividade e participação de pessoas com deficiência, incapacidades ou mobilidade reduzida, visando sua autonomia, independência, qualidade de vida e inclusão social (BRASIL, 2009, p. 27).

Fica evidente que a relevância das TAs para as PcDs é a melhora adquirida na acessibilidade dessas pessoas aos diversos ambientes que frequentam e na execução de atividades que fazem parte de suas vidas. As TAs promovem oportunidades a esse grupo socialmente excluído, fazendo com que as barreiras causadas pela deficiência sejam neutralizadas de maneira concreta. Mas, além disso, a TA propicia o combate ao preconceito, pois permite que a $\mathrm{PcD}$ possa interagir e realizar suas atividades em condições equivalentes à pessoa sem deficiência. A convivência social facilitada pela TA proporciona autoestima à PcD - já que esta pode expressar suas potencialidades e capacidades - e possibilita a eliminação de discriminações por meio do respeito construído nessas relações (DAMASCENO; GALVÃO FILHO, 2002).

Sendo assim, é fundamental averiguar a utilização da TA dentro das empresas que possuem PcDs em seu quadro de funcionários. Ela é um crucial recurso de adaptação ao ambiente de trabalho, mas, principalmente, um importante mediador social das relações vivenciadas dentro do ambiente organizacional e um recurso respeitável para garantir o treinamento e desenvolvimento das PcDs.

\section{MÉTODO}

Este estudo adotou o método de pesquisa qualitativo. Foi feito um estudo de caso com duas instituições, visando checar as duas realidades de forma comparativa e complementar. Ainda, para enriquecer a pesquisa, alguns dados foram submetidos a uma análise estatística descritiva.

\subsection{Local}

REAd | Porto Alegre - Edição 82 - N 3 - setembro/dezembro 2015 - p. 689-718 


\section{O TRABALHADOR COM DEFICIÊNCIA NA ORGANIZAÇÃO: UM ESTUDO SOBRE O TREINAMENTO E DESENVOLVIMENTO E A ADEQUAÇÃO DAS CONDIÇÕES DE}

\section{TRABALHO}

A pesquisa foi realizada com duas empresas do setor privado de um município do interior de Minas Gerais. Foram escolhidas empresas que possuíam mais de 100 funcionários, incluindo trabalhadores com deficiência. As duas empresas estão entre as três maiores da cidade. A fim de manter o anonimato das empresas e para fins da pesquisa, elas foram nomeadas como Empresa 1 e Empresa 2.

\subsection{Participantes}

A pesquisa foi realizada com dois grupos amostrais. Um grupo foi formado por todos os profissionais que trabalham no setor de Recursos Humanos (RH) e no setor de Segurança no Trabalho (ST), e o segundo foi composto por todos os trabalhadores com deficiência das empresas pesquisadas. A escolha do primeiro grupo amostral se justificou por serem funcionários dos setores responsáveis pelo T\&D e pela implementação de recursos de tecnologia assistiva, respectivamente.

Na Empresa 1, foram entrevistados três trabalhadores do $\mathrm{RH}$, um da ST e dois trabalhadores com deficiência. Já na Empresa 2, foram entrevistados quatro profissionais do RH, três da ST e seis trabalhadores com deficiência.

\subsection{Instrumentos e procedimentos para a coleta de dados}

O primeiro passo foi a submissão da proposta da pesquisa à Comissão de Ética em Pesquisas Envolvendo Seres Humanos (CEPES) da Universidade Federal de São João delRei. Após a aprovação, iniciou-se a pesquisa

Num primeiro momento, foi feito contato com o responsável pelo RH de cada empresa e, a partir desse contato, agendadas as entrevistas com todos os participantes. Primeiro foi realizado um levantamento das informações sobre a empresa junto ao coordenador do RH e, em seguida, realizadas as entrevistas, juntamente com a aplicação dos questionários. A coleta de dados requereu de duas a três visitas em cada empresa.

Foram expostos aos entrevistados todos os dados que envolvem a pesquisa, bem como o caráter voluntário da participação dos mesmos. Explicados todos esses pontos, eles foram convidados a assinar o Termo de Consentimento Livre e Esclarecido.

REAd | Porto Alegre - Edição 82 - N 3 - setembro/dezembro 2015 - p. 689-718 
Para a coleta de dados, foram realizadas entrevistas semiestruturadas com todos os participantes que, totalizaram sete profissionais de $\mathrm{RH}$, quatro profissionais de ST e oito trabalhadores com deficiência.

Além das entrevistas, foram utilizados quatro questionários e dois inventários.

Dois dos questionários, de caráter sociodemográfico, foram aplicados nos trabalhadores com deficiência e nos profissionais de RH e de ST a fim de levantar o perfil dos mesmos.

O terceiro foi para a caracterização das empresas onde as pesquisas ocorreram. As informações desse questionário foram completadas por meio de análises documentais.

O outro foi construído para fins desta pesquisa, baseado no Modelo de Avaliação Integrado e Somativo - MAIS (BORGES-ANDRADE, 2006) e nomeado Questionário de Avaliação de Treinamento e Desenvolvimento de Trabalhadores com Deficiência - ATDTD. Ele foi aplicado nos profissionais de $\mathrm{RH}$, e estes deveriam marcar a frequência com que as ações eram realizadas - raramente, às vezes, frequentemente ou sempre. Nele, são encontradas ações em forma de afirmações baseadas nos oito componentes que integram o MAIS. Após a elaboração das questões, o questionário foi avaliado por especialistas da área, que fizeram suas sugestões, e estas foram adequadas ao questionário.

Também, foram aplicados dois inventários aos profissionais do setor de RH e de ST: o Inventário de Concepções de Deficiência em Situações de Trabalho e o Inventário de Ações de Adequação das Condições e Práticas de Trabalho, que abordam a percepção deles sobre as PcDs e analisam os aspectos que precisam ser planejados e modificados para melhorar as condições de trabalho das PcDs, respectivamente.

O Inventário de Concepções de Deficiência em Situações de Trabalho - ICD-ST (CARVALHO-FREITAS, 2012) foi construído com base nas Concepções de Deficiência identificadas por Carvalho-Freitas (2007). Inicialmente, o Inventário contemplava sete fatores por meio de 22 questões. Porém, após um estudo realizado por Carvalho-Freitas e Marques (2010), verificou-se que o fator necessidade de treinamento não estava empiricamente relacionado ao construto de concepções de deficiência em situações de trabalho e foi retirado do Inventário. Sendo assim, o Inventário, hoje, possui 19 questões distribuídas entre seis fatores: 1) Benefícios da contratação; 2) Vínculo; 3) Percepção do desempenho; 4) Concepção baseada em pressupostos da Normalidade; 5) Concepção baseada em pressupostos da Inclusão e; 6) Concepção espiritual. 


\section{O TRABALHADOR COM DEFICIÊNCIA NA ORGANIZAÇÃO: UM ESTUDO SOBRE O TREINAMENTO E DESENVOLVIMENTO E A ADEQUAÇÃO DAS CONDIÇÕES DE}

\section{TRABALHO}

Os Fatores 4, 5 e 6 estão diretamente relacionados a três matrizes de concepções de deficiência - matriz da normalidade, matriz espiritual e matriz da inclusão. Já os Fatores 1, 2 e 3 estão relacionados à matriz de interpretação denominada matriz técnica. A matriz da subsistência/sobrevivência foi excluída do Inventário por ser considerada uma matriz implícita em todas as demais, e a matriz da sociedade ideal e da função instrumental da pessoa também não foi incluída pelo fato de seus pressupostos serem considerados antiéticos e improváveis de serem admitidos pelos respondentes.

O Inventário de Ações de Adequação das Condições e Práticas de Trabalho (IACPT) também foi construído e validado por Carvalho-Freitas (2009). Sendo a organização social do espaço um aspecto importante para os estudos de deficiência, esse Inventário torna-se fundamental por ser utilizado no diagnóstico e planejamento de ações de inserção nas empresas. O Inventário é composto por três fatores, distribuídos em 13 questões. São eles:

1) Sensibilização: este fator avalia a percepção das pessoas sobre as ações da organização quanto à sensibilização das chefias e funcionários para a inserção de PcDs e ao fornecimento de informações às PcDs contratadas sobre saúde e segurança no trabalho.

2) Adaptações das condições de trabalho: este fator indica a percepção das pessoas em relação às adaptações nas condições e instrumentos de trabalho na organização visando à inserção de PcDs.

3) Adequação das práticas de recursos humanos: este fator focaliza a percepção das pessoas quanto à adequação das práticas de RH (seleção, treinamento e promoção, entre outras) realizadas para a inserção das PcDs na organização.

As entrevistas foram realizadas individualmente em salas restritas cedidas pelas próprias empresas. Já a análise documental foi realizada com material cedido pela própria empresa e também em seus sites na internet.

\subsection{Procedimentos de análise}

Para a análise dos dados foi realizada análise de conteúdo das entrevistas e dos questionários.

A análise de conteúdo utiliza procedimentos sistemáticos e objetivos de descrição do conteúdo das mensagens, indicadores - quantitativos ou não - que permitem a inferência de conhecimentos relativos às condições de produção/recepção (variáveis inferidas) dessas 
mensagens. O método se organiza em três momentos fundamentais: a pré-análise, a exploração do material e o tratamento dos resultados (BARDIN, 1977). Após a realização desses passos, as mensagens inferidas no último momento foram apoiadas no referencial teórico adotado.

Os questionários também foram submetidos a uma análise estatística descritiva, a fim de levantar as médias dos dados e descrevê-los de forma mais ilustrativa.

A tabela 1 resume o método utilizado.

Tabela 1 - Objetivos/propostas da pesquisa e as respectivas técnicas para coleta e análise de dados

\begin{tabular}{|c|c|c|c|}
\hline OBJETIVO/ PROPOSTA & $\begin{array}{l}\text { COLETA DE } \\
\text { DADOS }\end{array}$ & $\begin{array}{l}\text { ANÁLISE DE } \\
\text { DADOS }\end{array}$ & $\begin{array}{l}\text { RESPONDENTES/ } \\
\text { FONTE }\end{array}$ \\
\hline Descrever e conhecer a empresa & $\begin{array}{c}\text { Entrevista / } \\
\text { Análise documental }\end{array}$ & $\begin{array}{l}\text { Análise de conteúdo/ } \\
\text { Interpretação dos } \\
\text { dados }\end{array}$ & $\begin{array}{l}\text { Responsável pelo RH } \\
\text { Sites e documentos da } \\
\text { empresa }\end{array}$ \\
\hline $\begin{array}{l}\text { Verificar as práticas utilizadas pelo RH } \\
\text { das organizações no que se refere ao } \\
\text { treinamento e desenvolvimento das PcDs. }\end{array}$ & $\begin{array}{l}\text { Questionário } \\
\text { ATDTD/ } \\
\text { Entrevista }\end{array}$ & $\begin{array}{l}\text { Estatística descritiva/ } \\
\text { Análise de conteúdo }\end{array}$ & Profissionais do RH \\
\hline $\begin{array}{l}\text { Investigar a percepção de deficiência dos } \\
\text { profissionais do RH e da ST. }\end{array}$ & $\begin{array}{l}\text { Questionário } \\
\text { ICD-ST / } \\
\text { Entrevista }\end{array}$ & $\begin{array}{l}\text { Estatística descritiva/ } \\
\text { Análise de conteúdo }\end{array}$ & $\begin{array}{l}\text { Profissionais do RH e } \\
\text { da ST }\end{array}$ \\
\hline $\begin{array}{l}\text { Levantar o perfil dos trabalhadores com } \\
\text { deficiência, enfocando o nível de } \\
\text { escolaridade, a qualificação profissional, o } \\
\text { cargo e o tipo de deficiência. }\end{array}$ & $\begin{array}{l}\text { Questionário } \\
\text { sociodemográfico/ } \\
\text { Entrevista }\end{array}$ & $\begin{array}{l}\text { Estatística descritiva/ } \\
\text { Análise de conteúdo }\end{array}$ & PcDs \\
\hline $\begin{array}{l}\text { Investigar a percepção das PcDs acerca do } \\
\text { T\&D desenvolvido pelo RH, assim como } \\
\text { suas perspectivas de crescimento dentro } \\
\text { da empresa. }\end{array}$ & Entrevista & Análise de conteúdo & PcDs \\
\hline $\begin{array}{l}\text { Verificar se as organizações utilizam } \\
\text { recursos de tecnologia assistiva e como } \\
\text { estes têm contribuído para a adaptação das } \\
\text { PcDs no ambiente de trabalho e para seu } \\
\text { T\&D. }\end{array}$ & $\begin{array}{l}\text { Questionário ATDTD } \\
\text { (questão 33) / } \\
\text { Entrevista }\end{array}$ & $\begin{array}{l}\text { Estatística descritiva/ } \\
\text { Análise de conteúdo }\end{array}$ & $\begin{array}{l}\text { Profissionais do RH/ } \\
\text { Profissionais da ST/ } \\
\text { PcDs }\end{array}$ \\
\hline $\begin{array}{l}\text { Conhecer a percepção dos trabalhadores } \\
\text { com deficiência e dos profissionais sobre } \\
\text { as práticas de inclusão e adaptação das } \\
\text { PcDs no ambiente de trabalho. }\end{array}$ & $\begin{array}{l}\text { Questionário IACPT / } \\
\text { Entrevista }\end{array}$ & $\begin{array}{l}\text { Estatística descritiva/ } \\
\text { Análise de conteúdo }\end{array}$ & $\begin{array}{l}\text { Profissionais do RH/ } \\
\text { Profissionais da ST/ } \\
\text { PcDs }\end{array}$ \\
\hline
\end{tabular}

Fonte: os autores.

\section{RESULTADOS E DISCUSSÃO}

\subsection{Caracterização das empresas}




\section{O TRABALHADOR COM DEFICIÊNCIA NA ORGANIZAÇÃO: UM ESTUDO SOBRE O TREINAMENTO E DESENVOLVIMENTO E A ADEQUAÇÃO DAS CONDIÇÕES DE}

\section{TRABALHO}

A Empresa 1 é a menor entre as duas visitadas. Ela é a filial de uma empresa localizada em outro estado do Brasil embora a matriz atenda por uma razão social diferente há cinco anos. Trabalha com metalurgia; especificamente, estanho.

Possui três programas de responsabilidade social, em que um é voltado para os funcionários da empresa (“O lugar do seu filho é na escola”), outro para a comunidade (“Campanha do cobertor”) e o terceiro para ambos os públicos (“Viagem na leitura”).

Ela possui 88 funcionários ativos na empresa, sendo dois deles com deficiência.

Um ponto a se ressaltar, e que é de grande interesse para esta pesquisa, é a política de inclusão de PcDs adotada pela empresa. Na Empresa 1, o grande motivador para a contratação de trabalhadores com deficiência na empresa é o cumprimento da legislação, mais especificamente a Lei de Cotas. Embora tenha sido declarado um número de funcionários inferior a 100 (88 funcionários ativos), a obrigatoriedade da lei se deve ao fato de incluir no número total de funcionários os da matriz e os da filial.

Já a segunda empresa pesquisada faz parte de um grupo que possui outras filiais em outros países. No Brasil, é a única representante do grupo. Seu ramo de atividade é a metalurgia e a química.

Embora ela não possua nenhum programa específico de responsabilidade social, a empresa promove ações sociais isoladas voltadas para a comunidade; por exemplo, ajudar a APAE da cidade.

Hoje, possui 205 funcionários, sendo seis deles com deficiência. Durante a realização da pesquisa, ela estava em processo de recrutamento de mais um funcionário com deficiência.

Quanto à questão da inclusão de pessoas com deficiência, a empresa não se pauta prioritariamente no cumprimento de cotas. Mesmo assim, a empresa possui a cota para PcDs completa e está em processo de contratação de mais uma. O processo de recrutamento de PcDs é feito de acordo com o surgimento de candidatos em potencial no mercado. Há uma constante busca de profissionais com deficiência - seja pela parceria com a APAE e com universidades ou por meio de bancos de currículos da empresa - e, quando algum candidato se aproxima do perfil da empresa, possíveis vagas são negociadas com a diretoria. Da mesma forma, se durante um processo de recrutamento "normal” aparece um candidato com deficiência, ele é avaliado normalmente como os outros.

Analisando a política de inclusão das empresas, constatou-se que na Empresa 1 a Lei de Cotas é o motivador para a contratação de PcDs. Na Empresa 2, embora se tenha a 
influência da Lei, a contratação de PcDs baseia-se na busca de candidatos em potencial e na negociação de vagas com a diretoria.

Mesmo com a Lei, o tipo de deficiência também influencia na contratação (o que ficou mais claro na Empresa 1), o que torna a concretização da Lei parcial e excludente, segundo Ribeiro e Carneiro (2009). Para eles, como não há exigência quanto ao tipo de deficiência, opta-se pelas mais convenientes, discriminando as pessoas com deficiências mais graves como, por exemplo, “os cegos, os surdos, os doentes mentais e os cadeirantes” (p. 562). Dessa forma, a dificuldade de acesso ao mercado de trabalho não está relacionada apenas a possuir deficiência, mas ao tipo de deficiência, que pode limitar ou aumentar as chances de conquistar uma vaga (COSTA et al., 2011).

\subsection{Caracterização da amostra}

Quanto ao perfil dos profissionais que trabalham nas duas empresas, os que trabalham no RH são unanimemente do sexo feminino e os que trabalham na área de ST, masculinos. Na Empresa 1, os entrevistados trabalham há mais de cinco anos na empresa, enquanto, na Empresa 2, dois (30\%) dos entrevistados trabalham há menos de um ano na empresa. A formação dos profissionais em ambas as empresas é variada, sendo que, na Empresa 1, 50\% possuem pós-graduação e, na Empresa 2, a maioria dos profissionais. Além disso, na Empresa 1, metade dos entrevistados trabalha diretamente com trabalhadores com deficiência e, na Empresa 2, todos os entrevistados relataram conviver diretamente com pelo menos um trabalhador com deficiência.

Já os trabalhadores com deficiência, tanto de uma empresa quanto da outra, são do sexo masculino. A deficiência que os trabalhadores da Empresa 1 possuem é a intelectual e, na Empresa 2, metade possui deficiência intelectual e a outra metade, deficiência física/motora. Na Empresa 1, as PcDs possuem baixa escolaridade e ocupam cargos operacionais; na Empresa 2, a escolaridade varia desde o Ensino Fundamental incompleto ao Ensino Superior incompleto, e elas ocupam cargos variados - auxiliar administrativo, operador e auxiliar contábil.

\subsection{Práticas de T\&D utilizadas pelo RH}

REAd | Porto Alegre - Edição 82 - Nº 3 - setembro/dezembro 2015 - p. 689-718 


\section{O TRABALHADOR COM DEFICIÊNCIA NA ORGANIZAÇÃO: UM ESTUDO SOBRE O TREINAMENTO E DESENVOLVIMENTO E A ADEQUAÇÃO DAS CONDIÇÕES DE TRABALHO}

Ao se analisarem as práticas de T\&D utilizadas pelo RH, a avaliação de treinamento realizada baseada no MAIS demonstrou que na Empresa 1 os componentes mais trabalhados nos treinamentos com PcDs são disseminação, suporte, necessidades e resultados. É um resultado razoável, visto que metade dos componentes esperados são trabalhados.

Na Empresa 2, com exceção do componente efeitos a longo prazo, os demais foram identificados como realizados frequentemente. O resultado na Empresa 2 é excelente, já que quase todos os componentes estão presentes.

Como o componente efeitos a longo prazo não foi identificado em nenhuma das empresa, pode-se sugerir que, em função do tempo de empresa dos trabalhadores entrevistados, ou até mesmo dos trabalhadores com deficiência, os respondentes não tiveram condições de avaliar adequadamente esse componente, que demanda tempo de acompanhamento dos resultados após os treinamentos. Os componentes insumos, procedimentos e processos, que também não se apresentaram de forma efetiva na avaliação da Empresa 1, são importantes na complementação do planejamento das ações de treinamento.

Mesmo assim, a Empresa 1, assim como a Empresa 2, têm utilizado grande parte do MAIS e, com isso, alcançado um resultado satisfatório na opinião dos trabalhadores com deficiência e profissionais entrevistados.

Sobre o treinamento dos trabalhadores com deficiência, ambas relataram que eles foram submetidos ao treinamento de integração quando ingressaram na empresa. Na Empresa 1, eles não são submetidos a treinamentos de função. É realizado um acompanhamento diário com orientação de tarefas, além de um acompanhamento mensal feito com a APAE do município. Na Empresa 2, os treinamentos são por setores e dependem da necessidade, avaliada por meio do Levantamento de Necessidades de Treinamento (LNT) e da gestão de performance. Assim como na Empresa 1, a APAE também faz um acompanhamento mensal com os trabalhadores que possuem deficiência intelectual. Embora a Empresa 2 possua uma proposta de treinamento mais sistematizado, as duas utilizam o treinamento on-the-job, ou seja, o aprendizado das funções é feito na rotina de trabalho com o acompanhamento e a ajuda de pessoas que trabalham junto. Além disso, a parceria com a APAE é um recurso que auxilia as empresas a lidarem com um tipo de trabalhador com que ainda não sabem como lidar.

A melhora do desempenho das PcDs após submetidas aos treinamentos foi percebida pelos profissionais de RH da Empresa 1, que relacionaram as melhoras ao acompanhamento diário a que as PcDs são submetidas. Na Empresa 2, é percebida a melhora de desempenho 
apontada pelos entrevistados mediante novas conquistas feitas pelas PcDs no trabalho e pela motivação para desenvolver tarefas.

Outro ponto avaliado foi a qualificação das PcDs. Na Empresa 1, houve opiniões divergentes: enquanto a maioria colocou a qualificação como algo importante para a PcD, um dos profissionais - que, inclusive, lida diretamente com as PcDs - acha a qualificação desnecessária para o trabalhador que vai ingressar na empresa, pois prefere desenvolvê-lo dentro da empresa. Na Empresa 2, as opiniões, também, divergiram: para alguns, a qualificação não tem papel fundamental, já que os CHAs necessários podem ser trabalhados via treinamento e capacitação; para outros, a exigência de qualificação vai depender do cargo; e para outros, ela é vista como facilitador da socialização entre as PcDs e os outros funcionários, e pode diminuir o tempo gasto em repasses de instruções dadas pelos superiores às PcDs.

\subsection{Percepção das PcDs sobre o processo de T\&D}

Abordando a questão de como as PcDs percebem o processo de T\&D, na Empresa 1, os trabalhadores relataram não ter participado de treinamentos específicos do seu cargo na empresa ou mesmo em outra instituição por indicação dela. Entre as PcDs da Empresa 2, algumas participaram de cursos e de capacitações dentro e fora da empresa (financiados pela mesma); outras receberam a proposta, mas não se interessaram em fazer; e outras relataram nem sequer terem recebido esse tipo de proposta.

Os trabalhadores com deficiência da Empresa 1 perceberam melhora em seus relacionamentos interpessoais dentro da organização, além de melhora na execução de seu trabalho após se submeterem aos treinamentos (no caso deles, de acompanhamento diário). Na Empresa 2, os trabalhadores também perceberam melhora nos relacionamentos, sendo que a maioria relacionou melhora no trabalho após treinamentos, e alguns não.

No que tange ao crescimento profissional, as PcDs da Empresa 1 percebem possibilidades de crescimento na empresa e gostariam de continuar trabalhando nela. $\mathrm{Na}$ Empresa 2, embora muitos percebam possibilidades de crescimento, as opiniões das PcDs foram diversas: o crescimento profissional vai depender do esforço e capacidades próprios; alguns não pecebem possibilidade de crescer na empresa, ou por estarem próximos à aposentadoria, ou por não conclusão dos estudos; e um dos trabalhadores considera a possibilidade de mudar de empresa caso consiga um emprego melhor dentro da sua área, 


\section{O TRABALHADOR COM DEFICIÊNCIA NA ORGANIZAÇÃO: UM ESTUDO SOBRE O TREINAMENTO E DESENVOLVIMENTO E A ADEQUAÇÃO DAS CONDIÇÕES DE}

\section{TRABALHO}

enquanto os demais gostariam de ficar na empresa por estarem acostumados e se sentirem satisfeitos.

Os trabalhadores com deficiência da Empresa 1 se sentem satisfeitos por trabalhar na empresa e, também, valorizados embora um deles não se sinta tão valorizado pelo fato de sempre chamarem a atenção dele na frente dos outros funcionários. Na Empresa 2, a grande maioria das PcDs se sente valorizada e gosta de trabalhar na empresa. Apenas um dos funcionários se apresentou como desmotivado, principalmente por perceber que a empresa não valoriza todo o seu potencial. Apesar de algumas falas de insatisfação, de modo geral, os trabalhadores das duas empresas se encontram satisfeitos e realizados com o seu trabalho. Talvez, isso seja um reflexo da segregação sofrida por esse grupo durante muitos anos e que, diante da oportunidade de se mostrar produtivo no ambiente de trabalho, essa oportunidade lhe proporcione o sentimento de autovalorização e autoestima.

\subsection{Percepção de deficiência dos profissionais de RH e ST}

A questão analisada em seguida foi a percepção de deficiência dos profissionais de RH e ST. As concepções de deficiência encontradas na Empresa 1 foram representadas pela matriz técnica, da normalidade como matriz de interpretação dominante e da deficiência como fenômeno espiritual. A matriz da inclusão apresentou baixo resultado, demonstrando, assim, que os profissionais da empresa ainda percebem a deficiência como um problema da pessoa, e não do ambiente que precisa se adaptar a ela. Na Empresa 2, as concepções baseadas na matriz técnica e na matriz da inclusão social foram as que se destacaram. Na matriz técnica, a diversidade é um recurso técnico que deve ser bem administrado dentro do contexto organizacional. Assim, possibilitará não apenas a inclusão real das PcDs no trabalho, como também trará uma boa imagem para a organização perante clientes, funcionários e a sociedade em geral, além de propiciar um clima organizacional favorável. A matriz da normalidade demonstra que as pessoas percebem as PcDs como “desviantes” de um padrão de normalidade, refletindo situações embaraçosas no trabalho, segregação de PcDs em setores específicos da organização e problemas de relacionamento. Na matriz espiritual, as PcDs são marcadas pela segregação, dependentes da compaixão e caridade de outros, sem status moral e negadas em seus direitos de cidadãs, o que pode dificultar as relações de trabalho devido às possíveis diferenciações entre os trabalhadores com e sem deficiência. Já a matriz da inclusão

REAd | Porto Alegre - Edição 82 - Nº 3 - setembro/dezembro 2015 - p. 689-718 
reflete uma concepção de deficiência que valoriza o trabalhador com deficiência e percebe suas necessidades de estar em um ambiente adaptado.

Quanto às vantagens e desvantagens de contratação das PcDs, na Empresa 1 foram apontadas como vantagens: oportunidade para as PcDs mostrarem seu valor e crescimento interpessoal entre os funcionários que convivem com as diferenças; as desvantagens mencionadas foram: baixa produtividade e rendimento desses funcionários, e a exigênciade maior tolerância entre os colegas de trabalho das PcDs. Na Empresa 2, alguns profissionais disseram não haver nem vantagem e nem desvantagem, pois não percebem diferenciação entre trabalhadores com e sem deficiência. Outros entrevistados apontaram como vantagens a inserção social desse grupo e a presença de trabalhadores mais comprometidos e estusiasmados com o trabalho do que os sem deficiência, além de não notarem nenhuma desvantagem. As duas empresas ressaltaram a inclusão motivada por ações de responsabilidade social, e essa tem sido uma tendência percebida nas empresas brasileiras (BAHIA; SANTOS, 2009).

Ao serem questionados sobre o desempenho das PcDs, os entrevistados da Empresa 1 o perceberam como bom. A ideia de bom desempenho foi vinculada à superação de limites e à adaptação ao modo de trabalhar da empresa. Na Empresa 2, foram apresentadas diversas opiniões: é um desempenho bom, superando, muitas vezes, os dos funcionários sem deficiência; às vezes, em alguns casos, as PcDs têm comportamentos de estagnação e comodismo por terem sua vaga protegida pelo sistema de cotas; o desempenho não é melhor e nem pior do que o dos outros; e o desempenho está relacionado e vai depender das condições de trabalho.

Entre as dificuldades apontadas para a contratação e manutenção das PcDs, a Empresa 1 citou: a convivência dos colegas de trabalho com as PcDs e suas limitações e a adaptação física do ambiente (acessibilidade arquitetônica). Na Empresa 2, foram listadas: a falta de qualificação (tanto para contratar como para manter), a falta de vagas, a disputa das empresas pelos bons trabalhadores com deficiência, a falta de acessibilidade, o receio da empresa de a PcD não dar certo na empresa, a dificuldade de evacuação numa situação de emergência e a dificuldade de lotá-los em áreas que não ofereçam riscos ou não exijam esforços (dependendo da deficiência).

\subsection{Práticas de inclusão e adaptação das PcDs ao ambiente de trabalho}

REAd | Porto Alegre - Edição 82 - N 3 - setembro/dezembro 2015 - p. 689-718 


\section{O TRABALHADOR COM DEFICIÊNCIA NA ORGANIZAÇÃO: UM ESTUDO SOBRE O TREINAMENTO E DESENVOLVIMENTO E A ADEQUAÇÃO DAS CONDIÇÕES DE}

\section{TRABALHO}

O próximo tópico analisado foram as práticas de inclusão e adaptação das PcDs ao ambiente de trabalho. No IACPT, o fator sensibilização foi identificado pelos profissionais de RH e ST como o mais trabalhado na Empresa 1, significando que as informações recebidas pelos funcionários sobre saúde e segurança no trabalho são oferecidas de forma acessível, sem colocar em desvantagem as PcDs, e que, também, é realizada a sensibilização das chefias e grupos de trabalho com relação à inserção desse grupo. Já na Empresa 2, o fator percebido como mais trabalhado foi o de adequação das práticas de RH, de modo que os profissionais percebem que houve adequação das práticas de seleção, treinamento, promoção e transferência realizadas na organização com o intuito de inserir PcDs.

Sobre as adaptações realizadas na empresa para a inclusão das PcDs, as duas empresas relataram que nenhuma modificação estrutural foi feita, porém cada uma salientou pequenas intervenções e ajustes feitos. Na Empresa 1, as intervenções foram direcionadas a levar informações aos funcionários e chefes sobre as PcDs, as especificidades de cada deficiência e suas limitações. Na Empresa 2, foram realizadas pequenas adequações ergonômicas, como as feitas com os demais funcionários e a liberação de entrada dos trabalhadores com deficiência motora com seus automóveis nas dependências da empresa.

Quanto à relação entre desempenho e condições de trabalho, todos os respondentes ressaltaram que as adequações das condições de trabalho influenciam no bom desempenho dos funcionários, sejam elas de ordem física ou atitudinal. Na Empresa 1, um dos profissionais ressaltou que mais importante que a adaptação do ambiente é a escolha da pessoa que trabalhará com a PcD na empresa, pois ela terá papel fundamental no desenvolvimento desta.

No que diz respeito à participação dos profissionais de ST no processo de adaptação das PcDs, os profissionais das duas empresas não participaram de nenhuma adaptação. Eles relataram, porém, que, sempre que uma PcD está em processo de contratação, eles fazem um estudo das áreas possibilitadas de receber um trabalhador com deficiência, a fim de levantar os locais onde ela possa trabalhar.

Ainda sobre as adaptações, para os trabalhadores com deficiência da Empresa 1 nenhuma adaptação precisa ser implementada para uma melhor realização do seu trabalho. Para alguns trabalhadores com deficiência da Empresa 2, poderia ser realizada melhoria na acessibilidade (como a retirada de alguns degraus, que não impossibilitam, mas dificultam 
caminhar pela empresa) e, também, quanto ao modo de algumas pessoas (principalmente gestores) verem e tratarem a deficiência.

\subsection{As tecnologias assistivas nas empresas}

O útimo ponto analisado foi o das tecnologias assistivas nas empresas. Para os trabalhadores com deficiência das duas empresas, não há nenhum recurso ou equipamento adaptado à sua deficiência que precisa ser implantado ou adquirido pela empresa.

Os profissionais da Empresa 1 não sabiam o que é tecnologia assitiva e justificaram esse desconhecimento por não ser algo aplicável na realidade da empresa.

Entre os respondentes da Empresa 2, apenas um tinha noção do que se tratava, mas, mesmo assim, todos se mostraram desinformados sobre a questão.

Para o profissional de ST da Empresa 1, a implantação desse tipo de recurso depende da empresa e é algo que deve ser bem estudado antes de implantado, enquanto os profissionais de ST da Empresa 2 opinaram que a empresa deveria investir nesse tipo de recurso, independente do custo.

Tal resultado demonstra a relevância de levar ao conhecimento das empresas o que são as tecnologias assitivas e sua importância para um melhor desenvolvimento do trabalho das PcDs.

\section{CONSIDERAÇÕES FINAIS}

Este estudo buscou investigar como é realizado o treinamento e desenvolvimento das pessoas com deficiência dentro das organizações, abordando sua adaptação ao ambiente de trabalho, a partir da concepção dos trabalhadores com deficiência e dos profissionais de recursos humanos e de segurança do trabalho.

Dessa forma, a pesquisa buscou ampliar o conhecimento sobre as práticas de inclusão das pessoas com deficiência nas organizações, tomando como base de estudo duas empresas privadas de um município de Minas Gerais.

Os dados encontrados, de forma geral, demonstram que as empresas possuem uma disposição positiva para trabalhar com PcDs. As dificuldades mencionadas para a inclusão efetiva - como as barreiras arquitetônicas - foram encontradas em pesquisas semelhantes, como mencionado no decorrer deste estudo. Sendo a inclusão da diversidade um tema ainda 


\section{O TRABALHADOR COM DEFICIÊNCIA NA ORGANIZAÇÃO: UM ESTUDO SOBRE O TREINAMENTO E DESENVOLVIMENTO E A ADEQUAÇÃO DAS CONDIÇÕES DE} TRABALHO

novo no campo do trabalho, pode-se dizer que as empresas pesquisadas têm utilizado as estratégias disponíveis para promover essa inclusão.

Assim, o treinamento utilizado pelas empresas pesquisadas tem promovido o desenvolvimento dos trabalhadores com deficiência. Embora as estratégias de treinamento adotadas sejam comuns aos outros funcionários, sem a adoção de nenhum procedimento específico para as PcDs, elas têm refletido um bom resultado. Os profissionais de RH têm utilizado os recursos disponíveis (parceria com a APAE e treinamento on-the-job) para promover esta integração da PcD com a sua função.

As empresas, de modo geral, caminham para um processo de inclusão efetivo. Embora as concepções de deficiência que prevalecem na Empresa 1 sejam pautadas em paradigmas que focam o problema da deficiência na própria pessoa e não no ambiente, os profissionais percebem a importância de se adaptar o ambiente e oferecer condições necessárias para um bom desenvolvimento do trabalho. A Empresa 2, comparada à Empresa 1, se mostra mais preparada a vivenciar a inclusão da diversidade de forma mais humana.

As empresas sabem do valor das adaptações para as PcDs, assim como da utilização de TAs, embora não recorram a elas para promover o desenvolvimento de seus trabalhadores com deficiência. Para o tipo de deficiência apresentada por seus trabalhadores, esse tipo de recurso não se mostrou fundamental, como a própria fala das PcDs entrevistadas ressaltou. Porém, a não inclusão desses recursos e adaptações de maior porte no ambiente de trabalho tem restringido o acesso de trabalhadores com deficiências diversas às empresas. Com isso, por mais que as empresas entrevistadas tenham buscado formas de se adaptar à inclusão das PcDs, essa inclusão se mostra restrita e, portanto, ainda discriminante.

Embora a gestão da diversidade seja um desafio não só para as empresas pesquisadas, mas para as demais, é preciso investir, inovar e buscar ideias que proporcionem às PcDs verdadeiras oportunidades de inserção.

De fato, nenhum trabalhador com deficiência deixará de alcançar as metas e objetivos desejados se tiver ao seu alcance os recursos necessários.

Pela pesquisa, percebe-se que algumas empresas já se encaminham para uma inclusão consciente e coerente com a realidade das PcDs; outras ainda precisam trabalhar seus conceitos e percepções sobre a deficiência, mesmo depois de 23 anos da aprovação da Lei de Cotas.

REAd | Porto Alegre - Edição 82 - N 3 - setembro/dezembro 2015 - p. 689-718 
Torna-se fundamental o desenvolvimento de um trabalho com essas empresas, levando a elas conhecimento sobre a deficiência e as possibilidades de inclusão do trabalhador com limitações, incluindo a importância dos recursos de tecnologia assistiva.

\section{REFERÊNCIAS}

BARDIN, L. Análise de conteúdo. Lisboa: Edições 70. 1977.

BAHIA, M. S.; SANTOS, E. M. Práticas empresariais para a inclusão de pessoas com deficiência: um estudo de caso. In M. N. Carvalho-Freitas, \& A. L. Marques (Orgs.). Trabalho e Pessoas com Deficiência: pesquisas, práticas e instrumentos de diagnóstico. Curitiba: Juruá, p. 142-160, 2009.

BARNES, C. Understanding the social model of disability: past, present and future. In N. Watson, A. Roulstone, \& C. Thomas (Eds.). Routledge Handbook of Disability Studies. London: Routledge, p. 12-29, 2012.

BASTOS, A. V. B. Trabalho e qualificação: questões conceituais e desafios postos pelo cenário de reestruturação produtiva. In: J. E. Borges-Andrade, G. S. Abbad, \& L. Mourão (Orgs.). Treinamento, desenvolvimento e educação em organizações e trabalho: fundamentos para a gestão de pessoas. Porto Alegre: Artmed, p. 23-40, 2006.

BEZERRA, S. S.; VIEIRA, M. M. F. Pessoa com deficiência intelectual: a nova "ralé” das organizações do trabalho. Revista de Administração de Empresas, v. 52, n. 2, p.232-244, 2012.

BICKENBACH, J. E. The International Classification of Functioning, Disability and Health and its relationship to disability studies. In N. Watson, A. Roulstone, \& C. Thomas (Eds.). Routledge Handbook of Disability Studies. London: Routledge, p. 51-66, 2012.

BIRCHAL, S. O.; MUNIZ, R. M. A lógica do capitalismo e o trabalho humano. In I. B. Goulart (Org.). Psicologia organizacional e do trabalho: teoria, pesquisa e temas correlatos. São Paulo: Casa do Psicólogo, p. 43-54, 2010.

BORGES-ANDRADE, J. E. Avaliação integrada e somativa em TD\&E. In J. E. BorgesAndrade, G. S. Abbad, \& L. Mourão (Orgs.). Treinamento, desenvolvimento e educação em organizações e trabalho: fundamentos para a gestão de pessoas. Porto Alegre: Artmed, p. 343-358, 2006. 


\section{O TRABALHADOR COM DEFICIÊNCIA NA ORGANIZAÇÃO: UM ESTUDO SOBRE O TREINAMENTO E DESENVOLVIMENTO E A ADEQUAÇÃO DAS CONDIÇÕES DE TRABALHO}

BORGES-ANDRADE, J. E. et al. Treinamento, desenvolvimento e educação: um modelo para sua gestão. In L. O. Borges \& L. Mourão (Orgs.). O trabalho e as organizações: a partir da psicologia. Porto Alegre: Artmed, p. 465-496, 2013.

BRASIL. Secretaria Especial dos Direitos Humanos. Tecnologia Assistiva. 2009. Disponível em: <http://www.pessoacomdeficiencia.gov.br/app/sites/default/files/publicacoes/livrotecnologia-assistiva.pdf>. Acesso em: 14 nov. 2014.

Ministério da Fazenda. Censo Demográfico 2010: resultados gerais da amostra IBGE. (2012). Disponível em: <http://www.fazenda.gov.br/spe/publicacoes/ conjuntura/informativo_economico/2012/2012_04/outros/IE\%202012\%2004\%2027\%20CEN SO\%202010.pdf>. Acesso em: 5 out. 2012.

CARVALHO, M. L. Pessoas com deficiência e trabalho: (im) possibilidades da inclusão no capitalismo flexível. 2011. Disponível em:

<http://www.esocite.org.br/eventos/tecsoc2011/cd-anais/arquivos/pdfs/artigos/gt015pessoascom.pdf> Acesso em: 28 jul. 2014.

CARVALHO-FREITAS, M. N. A inserção de pessoas com deficiência em empresas brasileiras - Um estudo sobre as relações entre concepções de deficiência, condições de trabalho e qualidade de vida no trabalho. 2007. Tese (Doutorado em Administração) Universidade Federal de Minas Gerais, Belo Horizonte. 2007.

Ações de adequação das condições e práticas de trabalho para inserção de pessoas com deficiência. Psicologia para América Latina, México, n.16, jun. 2009. Disponível em: $<$ http://pepsic.bvsalud.org/scielo.php?pid=S1870-350X2009000100010\&script=sci_arttext $>$. Acesso em: 14 fev. 2014.

. Validação do Inventário de Concepções de Deficiência em Situações de Trabalho (ICD-ST). Psico-USF, v.17, n.1, p. 33-42, 2012.

CARVALHO-FREITAS, M. N.; LEAL, G. T.; SOUTO, J. F. Deficiência e Trabalho: Literatura Científica Internacional. Pesquisas e Práticas Psicossociais, v.6, n.1, p. 128-138, 2011.

CARVALHO-FREITAS, M. N.; MARQUES, A. L. A diversidade através da história: a inserção no trabalho de pessoas com deficiência. Revista Organizações \& Sociedade, v.14, n.41, p. 59-78, 2007. 
. Formas de ver as pessoas com deficiência: um estudo empírico do construto de concepções de deficiência em situações de trabalho. RAM, Revista de Administração Mackenzie, v.11, (3 ed. esp.), p. 100-129, 2010.

COIMBRA, C. E. P.; GOULART, I. B. Análise da inserção das pessoas com deficiência segundo suas percepções. In M. N. Carvalho-Freitas, \& A. L. Marques (Orgs.). Trabalho e Pessoas com Deficiência: pesquisas, práticas e instrumentos de diagnóstico. Curitiba: Juruá, p. 106-121, 2009.

COSTA, M. C. A. et al. Inclusão social pelo trabalho: a qualificação profissional para pessoas com deficiência intelectual. Gerais: Revista Interinstitucional de Psicologia, v.4, n.2, p. 200-214, 2011.

DAMASCENO, L. L.; GALVÃO FILHO, T. A. As novas tecnologias como tecnologia assistiva: utilizando os recursos de acessibilidade na educação especial. 2002. Disponível em: <http://www.ufrgs.br/niee/eventos/CIIEE/2002/programacao/Demonstracoes.pdf>. Acesso em: 11 jan. 2014.

DELGADO, M. C. S., \& GOULART, I. B. Práticas de desenvolvimento de pessoas com deficiência em uma instituição do setor educacional. Pesquisas e Práticas Psicossociais, v.6, n.1, p. 39-52, 2011.

FARIAS, N.; BUCHALLA, C. M. A Classificação Internacional de Funcionalidade, Incapacidade e Saúde da Organização Mundial da Saúde: conceitos, usos e perspectivas. Revista Brasileira de Epidemiologia, v.8, n.2, p. 187-193, 2005.

GARCIA, J. C. D.; GALVÃO FILHO, T. A. Pesquisa Nacional de Tecnologia Assistiva. São Paulo: Instituto de Tecnologia Social - ITS BRASIL e Ministério da Ciência, Tecnologia e Inovação - MCTI/SECIS, 2012.

GOULART, I. B.; COIMBRA, C. Inserção de pessoas com deficiência numa empresa de reflorestamento: um estudo de caso. In: ENCONTRO NACIONAL DA ANPAD, 32, 2008, Rio de Janeiro. Anais... Rio de Janeiro, 2008.

GOULART, I. B.; GUIMARÃES, R. F. Cenários contemporâneos do mundo do trabalho. In I. B. Goulart (Org.). Psicologia organizacional e do trabalho: teoria, pesquisa e temas correlatos. 3. ed. São Paulo: Casa do Psicólogo, p. 17-36, 2010.

MOURÃO, L.; PUENTE-PALACIOS, K. E. Formação profissional. In J. E. Borges-Andrade, G. S. Abbad \& L. Mourão (Orgs.). Treinamento, desenvolvimento e educação em 


\section{O TRABALHADOR COM DEFICIÊNCIA NA ORGANIZAÇÃO: UM ESTUDO SOBRE O TREINAMENTO E DESENVOLVIMENTO E A ADEQUAÇÃO DAS CONDIÇÕES DE TRABALHO}

organizações e trabalho: fundamentos para a gestão de pessoas Porto Alegre: Artmed, p. 4164, 2006.

RELAÇÃO ANUAL DE INFORMAÇÕES SOCIAIS (RAIS). Características do emprego formal segundo a Relação Anual de Informações Sociais. 2012. Disponível em: <http:// portal.mte.gov.br/data/files/FF808081419E9C900141B74A39245892/Principais\%20Resultad os\%20-\%20Ano\%20base\%202012\%202.pdf>. Acesso em: 31 jan. 2014.

RIBAS, J. B. C. Por que empregar pessoas com deficiência? In M. N. Carvalho-Freitas; A. L. Marques. Trabalho e pessoas com deficiência: pesquisas, práticas e instrumentos de diagnóstico. Curitiba: Juruá, p. 211-217, 2009.

RIBEIRO, M. A.; CARNEIRO, R. A inclusão indesejada: as empresas brasileiras face à Lei de Cotas para pessoas com deficiência no mercado de trabalho. Revista Organizações \& Sociedade, v.16, n.50, p. 545-564, 2009.

RIBEIRO, M. A.; RIBEIRO, F. Gestão organizacional da diversidade: Estudo de caso de um programa de inclusão de pessoas com deficiência. In M. N. Carvalho-Freitas; A. L. Marques (Orgs.). $O$ trabalho e as pessoas com deficiência: pesquisas, práticas e instrumentos de diagnóstico. Curitiba: Juruá, p. 122-141, 2009.

SECRETARIA DE DIREITOS HUMANOS. Portaria n. 2.344, de 3 de novembro de 2010. Regulamenta a substituição do termo “portador” para "pessoas com deficiência”. Disponível em: <http://www.udop.com.br/download/legislacao/trabalhista/pcd/port_2344_ pcd.pdf $>$. Acesso em 30 mar. 2014.

SHIMONO, S. O. Educação e trabalho: caminhos da inclusão na perspectiva da pessoa com deficiência. Dissertação (Mestrado em Educação) - Faculdade de Educação, Universidade de São Paulo, São Paulo. 2008.

SILVA, L. M. O estranhamento causado pela deficiência: preconceito e experiência. Revista Brasileira de Educação, v.11, n.33, p. 424-461, 2006.

SOUZA, D. C. T. Análise das práticas de recrutamento e de seleção de pessoas com deficiência para o trabalho em empresas privadas: cumprimento à Lei n. 8.213/1991. 2010. Dissertação (Mestrado em Educação) - Centro de Educação e Humanidades, Faculdade de Educação, Universidade do Estado do Rio de Janeiro, Rio de Janeiro. 2010. 
STONE-ROMERO, E. F., STONE, D. L.; LUKASZEWSKI, K. The influence of disability on role-taking in organizations. In: A. M. Konrad, P. Prasad; J. K. Pringle (Eds.). Handbook of workplace diversity. London: Sage, p. 401-430, 2006.

SUZANO, J. C. C. et al. Análise da produção acadêmica nacional dos últimos 20 anos sobre a inserção da Pessoa Portadora de Deficiência no mercado de trabalho. In M. N. CarvalhoFreitas; A. L. Marques (Orgs.). Trabalho e Pessoas com Deficiência: pesquisas, práticas e instrumentos de diagnóstico. Curitiba: Juruá, p. 23-42, 2009.

TANAKA, E. D. O.; MANZINI, E. J. O que os empregados pensam sobre o trabalho da pessoa com deficiência? Revista Brasileira de Educação Especial, v.11, n.2, p. 273-294, 2005.

VARGAS, M. R. M. Treinamento e desenvolvimento: reflexões sobre seus métodos. Revista de Administração, v.31, n.2, p. 126-136, 1996.

VARGAS, M. R. M.; ABBAD, G. S. Bases conceituais em treinamento, desenvolvimento e educação - TD\&E. In J. E. Borges-Andrade; G. S. Abbad; L. Mourão (Orgs.). Treinamento, desenvolvimento e educação em organizações e trabalho: fundamentos para a gestão de pessoas. Porto Alegre: Artmed, p. 137-158, 2006. 